\title{
Pediatric bone marrow transplantation: Psychopathologic features in recipients along with siblings
}

\author{
Semih Erden ${ }^{1}$ (D) | Bülent Barış Kuşkonmaz ${ }^{2}$ | Duygu Uçkan Çetinkaya ${ }^{2}$ | Fatih Ünal ${ }^{3}$ | \\ Berna Özsungur ${ }^{3}$
}

${ }^{1}$ Department of Child and Adolescent Psychiatry, Necmettin Erbakan University Faculty of Medicine, Konya, Turkey

${ }^{2}$ Department of Child Health and Diseases Hematology Unit, Hacettepe University Faculty of Medicine, Ankara, Turkey

${ }^{3}$ Department of Child and Adolescent Psychiatry, Hacettepe University Faculty of Medicine, Ankara, Turkey

Correspondence

Semih Erden, Department of Child and Adolescent Psychiatry, Necmettin Erbakan University Faculty of Medicine, Konya 42080, Turkey.

Email: semihe84@gmail.com

\begin{abstract}
Objective: To analyze the development of psychopathology in recipients along with their donor and nondonor siblings and the relationship with the bone marrow transplantation (BMT) process.

Methods: All children were interviewed using the Kiddie Schedule for Affective Disorders and Schizophrenia to assess psychopathology. The depression and anxiety symptoms and self-esteem of children and adolescents were evaluated using the Children's Depression Inventory, State-Trait Anxiety Inventory for Children, State-Trait Anxiety Inventory, and Rosenberg Self-Esteem Scale.

Results: In this study, the depressive symptom level was found significantly higher in the donor group compared with the nondonor group. State anxiety symptoms were higher in the BMT group $(P<.05)$. There were no significant differences in trait anxiety symptoms. Self-respect was higher in children in the donor group compared with those in the BMT group $(P<.05)$. During the transplant process, children with bone marrow transplants had a higher prevalence of depression, anxiety disorder, and attention-deficit/hyperactivity disorder, and nondonor siblings had a higher prevalence of depressive disorder, anxiety disorder, and attention-deficit/hyperactivity disorder compared with society in general.
\end{abstract}

Conclusion: Physicians should deal with the family as a whole, not just their patient, and should be aware of the psychiatric risk of other siblings during the assessment.

\section{KEYWORDS}

anxiety, bone marrow transplantation, cancer, depression, oncology, pediatric, child, psychopathology, self-esteem

\section{1 | INTRODUCTION}

Bone marrow transplantation (BMT) is the preferred treatment choice for life-threatening pediatric cancers, blood diseases, and metabolic disorders after failure of traditional treatments or recurrence of disease. ${ }^{1}$

It is known that anxiety increases during the many transplantation preparation procedures in children. ${ }^{2}$ Pot-Mees et al reported that anxiety, depression, peer isolation, and behavior problems such as aggression were seen in $15 \%$ of children before and after BMT. ${ }^{3}$ Depression was increased during the admission and months of hospital course after BMT. ${ }^{2-4}$ However, the majority of survivors can only return to school 1 year after BMT and show lower academic levels compared with their peers. ${ }^{3}$ It was shown that emotional and social problems continue in the long term. 5,6 
Although there are an increasing number of pediatric stem cell donor siblings, there are limited data related to the psychosocial adjustment of pediatric donor siblings. It was shown that during tissue-typing processes, ambivalence, and irritable feelings are common among donor children. Younger siblings find tissue typing scary and painful and as a result may not want to be donors. ${ }^{7}$ Donor siblings are reported to experience identity problems, withdrawal, guilt, anger, rage, and feel responsible for the success of the transplantation during the donation procedure. ${ }^{8,9}$ Contrary to this, MacLeod et al stated that for donor siblings with successful transplantation, the transplant positively affected life in a variety of ways, brought families closer together, and improved relationships with the recipient sibling. ${ }^{10}$

The BMT process may affect the nondonor sibling. A study of 21 donor and 23 nondonor siblings aged 6 to 18 years showed that nondonor siblings had high levels of anxiety. ${ }^{9}$ Nondonor children are as affected as donor siblings and are also found to have signs of depression. ${ }^{11} \mathrm{~A}$ study assessing isolation, anger, and depression signs in siblings found no significant difference between donor and nondonor siblings. ${ }^{12}$

In this study, we sought to analyze the development of psychopathology in BMT recipients along with their donor and nondonor siblings and to determine whether this process affected donor siblings more than nondonor siblings. The frequency and severity of psychological symptoms in BMT recipients and their siblings were reported earlier based on psychometric data. However, in most of these reports, diagnostic confirmation was lacking. In this study, we aimed to overcome this problem by using a structured diagnostic interview scale to examine the psychopathologies of donor and nondonor siblings along with the recipient sibling.

\section{2 | MATERIAL AND METHOD}

\section{1 | Sample}

The research group comprised 30 children and one of their parents who accepted to participate in the study after the aim and procedures were explained. The children, who were still in remission, were aged 6 to 18 years and had undergone BMT in the Hacettepe University Children Hospital BMT Unit. Most of the children included in the study had transplantation due to blood diseases, the remainder underwent transplantation due to immune deficiencies, the distribution of which is shown in Table 1. This study included two control groups. Group 1 was formed by children and adolescents who gave marrow to their siblings, and group 2 comprised children and adolescents who had a sibling undergoing transplantation but who were not ill or a donor themselves. The age of the children in the groups was between 6 and 18 years. Children and adolescents with any comorbid neurologic and/or chronic disease, with clinically proven cognitive impairment, and autism spectrum disorder or psychotic disorder were not included in the study.
TABLE 1 Distribution of diseases in the bone marrow transplantation (BMT) group

\begin{tabular}{lr}
\hline Disease & $\mathrm{n}$ \\
\hline Malign & 8 \\
Acute Myeloid Leukemia & 3 \\
Acute Lymphoblastic Leukemia & 2 \\
Myelodysplastic Syndrome & 2 \\
Juvenile Myelomonocytic Leukemia & 1 \\
\hline Nonmalignant & 22 \\
Fanconi Aplastic Anemia & 5 \\
Thalassemia Major & 7 \\
Aplastic Anemia & 3 \\
Hemophagocytic Syndrome & 3 \\
Osteopetrosis & 1 \\
Wiskott Aldrich Syndrome & 1 \\
Dock 8 Deficiency & 1 \\
Mitochondrial Neurogastrointestinal Encephalomyopathy & 1
\end{tabular}

\section{2 | Method}

This study was completed in Hacettepe University Children Hospital Department of Child and Adolescent Mental Health and Disease from 1 July 2015, to 30 September 2015. The study was approved by Hacettepe University Non-invasive Clinical Research Ethics Committee on 10 June 2015 (decision no. GO15/389-27). The records of all children monitored after BMT at Hacettepe University Department of Pediatric Hematology, BMT unit, were investigated. Children whose successful transplantation operation was completed at least 2 months previously were included in the study. First, the family was interviewed. Then, the recipient child and donor and nondonor siblings were interviewed if available. One interview was made with all families in this cross-sectional study. We interrogated two separate periods using the Kiddie Schedule for Affective Disorders and Schizophrenia (KSADS) for each child and family. The first period was the transplant process, which was defined as being from an active BMT candidate to undergoing BMT. The second period, the current period, was questioned after transplantation. The children then completed the self-report scales. No single anxiety scale covers the study age groups, thus two different anxiety scales were used. All children and parents taking part in the study were given information about the study and provided written consent.

\subsubsection{Instruments and measures}

\section{Demographic data and clinical history}

Intellectual disability of children and adolescents were clinically assessed by the researchers. A "Sociodemographic and Clinical Information Form" that was prepared by the researchers was used to obtain information of sociodemographic characteristics, along with developmental, mental disease, and medical history. 


\section{K-SADS-PL-Turkish form}

The Schedule for Affective Disorders and Schizophrenia for School Age Children, Present and Lifetime Version (K-SADS-PL), a semistructured interview method, was developed by Kaufman et al according to the Diagnostic and Statistical Manual of Mental Disorders, Third and Fourth Edition (DSM-III and DSM-IV) diagnostic criteria to identify past and current psychopathologies in children and adolescents. ${ }^{13}$ The Turkish version of the K-SADS-PL translation-retranslation, validity, and reliability studies were performed by Gökler et al. ${ }^{14}$

\section{Children's Depression Inventory}

Children's Depression Inventory (CDI) is the most commonly used psychometric scale in childhood depression. ${ }^{15} \mathrm{~A}$ high $\mathrm{CDI}$ score shows the severity of depression level. The pathologic cutoff score of the scale is suggested as 19 . The validity and reliability study for the child and parent forms in Turkey was completed by Öy. ${ }^{16}$

\section{State-Trait Anxiety Inventory for Children}

This inventory, developed by Spielberger in 1973, is a self-report scale with two subscales measuring state and trait anxiety of children in 20 items each. ${ }^{17}$ Low scores obtained on the scale show a state of calmness and peacefulness, with moderate mean scores showing tension and stress, whereas high scores show severe stress and anxiety. There is no cutoff point for State-Trait Anxiety Inventory for Children (STAIC). The acquired scores give an indication of symptom severity through group comparison. The Turkish adaptation, validity, and reliability study of the STAIC was performed by Özusta. ${ }^{18}$

\section{State-Trait Anxiety Inventory}

This self-report scale was developed by Spielberger et al with the aim of separately identifying the state and trait anxiety levels. ${ }^{19}$ The cutoff point of State Anxiety Sub Scale (STAI-S) is accepted as 39 to 40 . The validity and reliability study for the STAI for Turkey was completed by Öner and Le Compte. ${ }^{20}$

\section{Rosenberg Self-Esteem Scale}

This scale tool about self-esteem in adolescents was developed by Rosenberg in $1965 .^{21}$ The validity and reliability studies for Turkey were completed by Çuhadaroğlu in 1985 to allow the scale to be used for Turkish adolescents. ${ }^{22}$

\section{Hollingshead-Redlich Scale}

The Hollingshead-Redlich Scale (HRS) is used to determine the socioeconomic-sociocultural level of families. ${ }^{23}$ The Turkish adaptation of the scale was completed by Tiryaki. ${ }^{24}$ The scale is based on the occupational and educational status of the mother and father and is a general scale that reflects the highest level reached in a certain period.

\section{3 | DATA ANALYSES}

The test was used for parametric data, the ANOVA and MANOVA tests were used for variance analysis, the Pearson correlation test was used for data correlations, and the Mann-Whitney $U$ test, Kruskal-Wallis $\mathrm{H}$, and Spearman correlation tests were used for nonparametric data. All statistical analyses were performed using the Statistical Program for the Social Sciences version 15. Power analyses were performed for postintervention CDI (power 0.95; effect size 0.44), postintervention state anxiety (power 0.57; effect size 0.27), postintervention trait anxiety (power 0.92; effect size 0.42 ), and postintervention Rosenberg Self-Esteem Scale (RSES) (power 0.86; effect size 0.38).

\section{4 | RESULTS}

Sociodemographic information is given in Table 2. There were no significant differences found between the three groups in terms of age, sex, education, and socioeconomics-sociocultural levels. The distribution of psychopathology in the groups and between the groups is given in Tables S1 and S2.

\section{1 | Distribution of anxiety, depression, and self-esteem problems among the groups and between the groups}

It was observed that depressive symptom levels were statistically significantly higher in the donor group compared with the nondonor group ( $P=.013$ ). On the other hand, the depressive symptom level of the donor group was higher than in the recipient group, although not significant. When the scores obtained in all three groups were examined, each group was observed to obtain scores above the cutoff (Table 3).

When the groups were compared for anxiety levels, it was observed that state anxiety scores of the recipient group were statistically significantly higher compared with the nondonor group $(P=$ .050). On the other hand, state anxiety scores of the donor group were higher than nondonor group, although not significant. In terms of trait anxiety scores, there was no statistically significant difference between the groups. On the other hand, trait anxiety scores of donor and nondonor group were higher than the recipient group, although not significant.

Children in the donor group were identified to have statistically significantly higher self-esteem compared with the recipient group $(P=.048)$

\subsection{Correlations between total scale points in groups}

In the recipient group, there was a moderate positive correlation between the depression scale and persistence scores of the anxiety scale. In the donor group, there were positive correlations identified between the persistence scores of the anxiety scale and state anxiety scores and self-esteem scores. No significant correlation was detected between depression, anxiety, self-respect, and socioeconomic level scores for children in the nondonor group (Table 4). 
TABLE 2 Sociodemographic data of the groups

\begin{tabular}{|c|c|c|c|c|}
\hline & Recipient $(n=30)$ & Donor $(n=20)$ & Nondonor $(n=30)$ & Statistics \\
\hline Age (mo), Mean $( \pm S D)$ & $146.3(45.21)$ & $162.95(43.07)$ & $150.40(43.81)$ & $F=.373^{a}$ \\
\hline \multicolumn{5}{|l|}{ Sex, n (\%) } \\
\hline Female & $12(40)$ & $9(45)$ & $18(60)$ & $\chi^{2}=2.552$ \\
\hline \multicolumn{5}{|l|}{ Education, y } \\
\hline \multicolumn{5}{|l|}{ Maternal age } \\
\hline Mean $( \pm S D)$ & $40.17(7.57)$ & $40.65(5.14)$ & $38.73(4.14)$ & $F=.757^{a}$ \\
\hline \multicolumn{5}{|l|}{ Maternal education, y } \\
\hline Mean $( \pm S D)$ & $6.3(3.5)$ & $4.9(4.5)$ & $4.4(3.1)$ & $F=.129^{a}$ \\
\hline Mean $( \pm S D)$ & $9.5(3.7)$ & $8(4.6)$ & $7.6(3.6)$ & $F=.152^{\mathrm{a}}$ \\
\hline Diagnosis age, mo, median (range) & $69(3-190)$ & & & \\
\hline BMT age (range) & $88.5(9-195)$ & & & \\
\hline Duration between diagnosis-BMT (range) & $10.5(3-96)$ & & & \\
\hline Duration after BMT (range) & $36.5(2-126)$ & & & \\
\hline \multicolumn{5}{|l|}{ Graft-versus-host disease, n (\%) } \\
\hline Yes & $5(16.7)$ & & & \\
\hline No & 25 (83.3) & & & \\
\hline
\end{tabular}

Abbreviation: BMT, bone marrow transplantation.

${ }^{a}$ Not significant.

TABLE 3 Anxiety, depression, and self-esteem levels in the recipient and control groups

$\begin{array}{lcccc} & \text { Recipient }(\mathbf{n}=30) & \text { Donor }(\mathbf{n}=20) & \text { Nondonor }(\mathbf{n}=30) & \text { Statistics } \\ \text { CDI Mean }( \pm S D) & 23.67(5.71)^{\mathrm{ab}} & 27.75(10.57)^{\mathrm{a}} & 21.86(4.66)^{\mathrm{b}} & \mathrm{F}=4.304^{*} \\ \text { STAI-S Mean }( \pm S D) & 0.20(1.12)^{\mathrm{a}} & 0.24(0.77)^{\mathrm{ab}} & -0.39(0.87)^{\mathrm{b}} & \mathrm{F}=3.758^{*} \\ \text { STAI-T Mean ( } \pm \text { SD) } & -0.33(0.84) & 0.18(0.78) & 0.22(1.18) & 1(0-4)^{\mathrm{ab}} \\ \text { RSES Median (min-max) } & 1(0-3)^{\mathrm{a}} & 0(0-2)^{\mathrm{b}} & \chi^{2}=6.065^{*}\end{array}$

Abbreviations: CDI, Children's Depression Inventory; RSES, Rosenberg Self-Esteem Scale; SD, Standard Deviation; STAI-S, State Anxiety Inventory for Children; STAI-T, Trait Anxiety Inventory.

${ }^{a}$ Groups differing statistically on post-hoc assessments.

${ }^{\mathrm{b}}$ Not significant.

ab Were used to indicate two groups with statistically significant differences.

${ }^{*} P<.05$.

No statistically significant correlation was detected between socioeconomic levels and scale scores of the families in recipient, donor, and nondonor group. No significant relation was detected between duration after BMT and symptoms in the recipient group (Table 4).

\section{5 | DISCUSSION}

This study is the first study to use the K-SADS-PL semi-structured interview form to assess the psychopathologies of BMT recipients along with donor and nondonor siblings. In this study, during the 
TABLE 4 The correlation of scales between in recipient group

\begin{tabular}{|c|c|c|c|c|c|c|c|}
\hline & & CDI & STAI-S & STAI-T & RSES & HRS & BMT Time \\
\hline \multirow{4}{*}{ Recipient } & STAI-S & 0.340 & 1 & & & & \\
\hline & RSES & 0.024 & -0.201 & -0.091 & 1 & & \\
\hline & HRS & 0.155 & 0.291 & -0.097 & 0.303 & 1 & \\
\hline & BMT time & 0.147 & 0.196 & 0.024 & -0.081 & 0.077 & 1 \\
\hline \multirow{3}{*}{ Donor } & STAI-T & -0.168 & $0.581^{* *}$ & 1 & & & \\
\hline & RSES & -0.130 & 0.273 & $0.466^{*}$ & 1 & & \\
\hline & HRS & -0.125 & 0.058 & -0.169 & 0.127 & 1 & \\
\hline \multirow[t]{2}{*}{ Nondonor } & CDI & 1 & & & & & \\
\hline & STAI-S & -0.092 & 1 & & & & \\
\hline
\end{tabular}

Abbreviations: BMT time, duration after bone marrow transplantation; CDI, Children's Depression Inventory; HRS, Hollingshead-Redlich Scale; RSES, Rosenberg Self-Esteem Scale; STAI-S, State Anxiety Inventory for Children; STAI-T, Trait Anxiety Inventory.

${ }^{*} P<.05$.

${ }^{* *} P<.01$.

transplant process, children with bone marrow transplants had a higher prevalence of depression, anxiety disorder, and attention deficit hyperactivity disorder (ADHD), and nondonor siblings had a higher prevalence of the depressive disorder, anxiety disorder, and ADHD compared with Turkish national sample. Additionally, donor siblings were not found to be different from general society in terms of the prevalence of depressive disorder and anxiety disorder.

In the Western literature, the prevalence of psychiatric diseases in children and adolescents in the population is reported as $1 \%$ to $5 \%$ for depressive disorder, $5 \%$ for anxiety disorder, $5 \%$ for ADHD, $2 \%$ to $10 \%$ for oppositional defiant disorder (ODD), and $1 \%$ to $10 \%$ for enuresis. ${ }^{25-29}$ Similarly, the epidemiology prevalence of psychiatric diseases in children and adolescents in the Turkish national sample is reported as $1.5 \%$ for mood disorder, $5.3 \%$ for anxiety disorder, $12.4 \%$ for ADHD, $2.2 \%$ for ODD, and $2 \%$ enuresis. ${ }^{30}$ When we compared our study findings with these figures, depressive disorder rates were observed to be high in recipient patients in the period before transplantation. Anxiety disorder rates were found to be high in the period before transplantation compared with the Turkish population. In the recipient group, ADHD and ODD rates were high in the periods before and after transplantation compared with the Turkish population, and the enuresis rate was observed to be high in recipient patients in the period before transplantation.

The results show that children with BMT have higher risk in terms of the development of depressive disorder and anxiety disorder compared with the Turkish population during the transplant process; however, these problems reduce after successful transplantation. In the literature, there is one study that used a semi-structured interview for children undergoing BMT. This research used the K-SADS-PL and reported that the incidence of anxiety disorder was significantly higher for transplant children compared with healthy peers. ${ }^{31}$ A study by Zanato et al reported that children undergoing BMT had more attention problems compared with healthy peers. ${ }^{32}$ Although ADHD is a well-known neurodevelopmental disease, Nylander et al reported that the ADHD rate was higher in adolescents with chronic illness than in healthy adolescents. ${ }^{33}$ Our study also included children who underwent transplantation due to chronic disease.

When we compared our study findings with a Turkish national sample, depressive disorder rates were observed to be high in donor siblings in the period before and after transplantation. Anxiety disorder was observed after transplantation and was similar to the Turkish population. ADHD was observed to have a similar frequency to rates for Turkey. The enuresis rate was found to be high in the period before transplantation compared with after. In conclusion, the transplant process was found to have higher incidence of depressive disorder and enuresis in donor siblings compared with society, and similar incidences for ADHD and anxiety disorder. According to these results, donor siblings may be said to develop fewer psychopathologies compared with other siblings.

During the transplant process, nondonor siblings had a higher depressive disorder and anxiety disorder prevalence compared with the Turkish national sample, whereas after the transplant, in spite of a reduction in depressive disorder and anxiety disorder, it was still high. Even when compared with the Turkish population, the rate of ADHD and enuresis were high in the period before and after transplantation. It may be concluded that nondonor siblings during the BMT process have high rates of depressive disorder and anxiety disorder. Although the risk of developing depressive disorder decreases in recipients after discharge, it is found similar in nondonor siblings.

Pot-Mees et al reported that anxiety, depression, peer isolation, and behavior problems such as aggression were seen in 15\% of children before and after BMT. ${ }^{3}$ Depression is accepted to increase during hospital stays and subsequent months after BMT. ${ }^{2-4}$ For donor siblings, if the transplant process is unsuccessful, the most commonly 
expressed feelings are known to be anger, guilt, and accusations. ${ }^{10,12}$ In our study, depressive symptom scores of donor siblings were observed to be significantly high compared with nondonor siblings. Additionally, for all children and adolescents in the groups, scores were obtained above the cutoff for the depression scale. This result shows that the BMT process negatively affects both donor and nondonor siblings in addition to the recipient. Similar to our findings, there are studies reporting common feelings of loneliness and isolation in donor siblings. ${ }^{12}$ Again, our study supports the opinion that nondonor children are as affected as donor siblings and display signs of depression. ${ }^{11}$

It is known that the pre-admission process, which involves many procedures, causes increased anxiety in recipients before transplantation. Meyers et al reported that $40 \%$ of children experienced significant levels of anxiety. ${ }^{2}$ Hutt et al reported the long-term effects of transplantation on donors related to anxiety and worry. ${ }^{34}$ Packman et al in a study of 21 donor and 23 nondonor siblings aged from 6 to 18 years reported higher anxiety levels in nondonor siblings. ${ }^{9}$ Our results showed increased state anxiety in children undergoing transplantation. These results show the BMT process increases anxiety due to procedures and interventions before transplantation in children. Again, there are studies reporting increased anxiety and worry in nondonor siblings. ${ }^{9}$ In our study, state anxiety scores of recipients were observed to be significantly high compared with nondonor siblings. As a result, it can be said that the recipient's inclusion in the BMT process increased state anxiety compared with the nondonors excluded from the BMT process.

During BMT process, the child cannot attend school or participate in social activities and are reported to experience a reduction in selfesteem. ${ }^{35}$ In a study comparing donor siblings with successful or unsuccessful transplant processes, MacLeod et al found that donor siblings with successful transplant were positively affected in many ways in life by the transplant, with families brought closer together and improved relationships with each other. ${ }^{10}$ Contrary to this, donor children are reported to experience identity problems, withdrawal, guilt, anger, rage, and feelings of responsibility for the success of transplantation during the donation process. ${ }^{8,9}$ Another study reported that donor siblings had lower self-esteem compared with nondonor siblings. ${ }^{36}$ Our results showed that the self-esteem of donor siblings was significantly higher compared with their sick siblings. Additionally, the self-esteem of children in all three groups was high. Although the BMT process is a challenging process for the siblings, the successful completion of this process can be positively influenced by all siblings. In conclusion, most successful outcomes of the transplant process contribute positively to donor siblings, with BMT children and nondonor siblings.

Although children undergoing transplantation and adolescents had high scores in state anxiety scales, the assessment with the K-SADSPL observed current anxiety disorder diagnosis incidence was similar to the general population. Considering the fact that the treatment of children with transplantation in our study consisted of a successful group, it can be said that the children's daily functioning was improved and thus they were not diagnosed as having depression and anxiety.
Our study is important because it is the first study to assess the psychopathologies of donor and nondonor children, in addition to children undergoing transplantation, using the K-SADS-PL semistructured psychiatric interview form. This is one of the strengths of our study. This study is important due to the low number of studies researching psychopathologies in donor and nondonor siblings during the transplantation process. Another strength of the study is that because the patients were chosen from the same center, it may be considered that they received similar care and support during the transplant process.

\section{6 | CONCLUSION}

\section{1 | Study limitations}

There are three limitations to this study. The first is that due to the lack of a healthy control group, the psychopathology of the children was not assessed compared with peers. This limitation was addressed through comparison with data from the normal population. The second is that as the validity/reliability data of the DSM$V$ version of KSADS had not yet been published when the study was performed, although DSM-V has been in force since 2013; therefore, DSM-III and IV diagnostic criteria were used in the study, and the findings were stated based on DSM-IV. The other limitation is that the duration from transplant until the time of the study differed case by case, which makes it difficult to associate findings after discharge with the BMT process. As the time after transplantation increases, the probability of being affected by psychological changes in children as well as different variables will increase.

\section{2 | Clinical implications}

In conclusion, it can be said that donor and nondonor siblings together with transplanted children are at risk for developing psychiatric disease. Clinicians should be aware of the psychology of the siblings as well as the sick child during the transplant process. Future studies may investigate factors that affect the development risk of the psychiatric disease of the recipient and the donor and nondonor siblings in the transplantation process.

\section{CONFLICT OF INTEREST}

The author(s) declared no potential conflicts of interest with respect to the research, authorship, and/or publication of this article.

\section{FUNDING INFORMATION}

The author(s) received no financial support for the research, authorship, and/or publication of this article.

\section{ORCID}

Semih Erden (1) https://orcid.org/0000-0002-7723-9584 


\section{REFERENCES}

1. Barrera M, Pringle LB, Sumbler K, Saunders F. Quality of life and behavioral adjustment after pediatric bone marrow transplantation. Bone Marrow Transplant. 2000;26(4):427-435.

2. Meyers CA, Weitzner M, Byrne K, Valentine A, Champlin RE, Przepiorka D. Evaluation of the neurobehavioral functioning of patients before, during, and after bone marrow transplantation. $J$ Clin Oncol. 1994;12(4):820-826.

3. Pot-Mees CC. The psychosocial effects of bone marrow transplantation in children. Eburon Delft; 1989.

4. Phipps S, Dunavant M, Lensing S, Rai SN. Acute health-related quality of life in children undergoing stem cell transplant: II. Medical and demographic determinants. Bone Marrow Transplant. 2002; 29(5):435-442.

5. Felder-Puig R, Peters C, Matthes-Martin S, et al. Psychosocial adjustment of pediatric patients after allogeneic stem cell transplantation. Bone Marrow Transplant. 1999;24(1):75-80.

6. Nespoli L, Verri A, Locatelli F, Bertuggia L, Taibi RM, Burgio GR. The impact of paediatric bone marrow transplantation on quality of life. Qual Life Res. 1995;4(3):233-240.

7. Kinrade LC. Preparation of sibling donor for bone marrow transplant harvest procedure. Cancer Nurs. 1987;10(2):77-81.

8. Wiley FM, Lindamood MM, Pfefferbaum-Levine B. Donor-patient relationship in pediatric bone marrow transplantation. J Assoc Pediatr Oncol Nurses. 1984;1(3):8-14.

9. Packman WL, Crittenden MR, Schaeffer E, Bongar B, Fischer JB, Cowan MJ. Psychosocial consequences of bone marrow transplantation in donor and nondonor siblings. J Dev Behav Pediatr. 1997; 18(4):244-253.

10. MacLeod KD, Whitsett SF, Mash EJ, Pelletier W. Pediatric sibling donors of successful and unsuccessful hematopoietic stem cell transplants (HSCT): a qualitative study of their psychosocial experience. J Pediatr Psychol. 2003;28(4):223-230.

11. Packman WL, Beck VL, VanZutphen KH, Long JK, Spengler G. The human figure drawing with donor and nondonor siblings of pediatric bone marrow transplant patients. Art Ther. 2003;20(2):83-91.

12. Gardner GG, August CS, Githens J. Psychological issues in bone marrow transplantation. Pediatrics. 1977;60(4):625-631.

13. Kaufman J, Birmaher B, Brent D, et al. Schedule for affective disorders and schizophrenia for school-age children-present and lifetime version (K-SADS-PL): initial reliability and validity data. J Am Acad Child Adolesc Psychiatry. 1997;36(7):980-988.

14. Gökler B, Ünal F, Pehlivantürk B, et al. Reliability and validity of schedule for affective disorders and schizophrenia for school age childrenpresent and lifetime version-Turkish version (K-SADS-PL-T). Turk $J$ Child Adolesc Mental Health. 2004;11(3):109-116.

15. Kovacs M. Children's depression inventory: Multi-Health Systems North Tonawanda. NY; 1992.

16. Oy B. Çocukluk depresyonu; Tarihçe, sınıflandırma ve tanı ölçütleri. Turk Psikiyatri Derg. 1990;1(2):21-23.

17. Spielberger CD, Edwards CD. State-trait anxiety inventory for children: STAIC: how I feel questionnaire: Professional manual: Mind Garden; 1973.

18. Ozusta S. Cocuklar için Durumluk-Surekli Kaygi Envanteri'nin uyarlama, gecerlik ve guvenirlik calismasi. Turk Psikoloji Dergisi. 1995; 10:32-44.

19. Spielberger C, Gorsuch R, Lushene R, et al. State-trait anxiety inventory. Palo Alto. CA: Consulting Psychologists Press; 1970.

20. Öner N, Le Compte A. Handbook of state-trait anxiety. Istanbul, Turkey: Bogazici University Publication; 1983.
21. Rosenberg M. Rosenberg self-esteem scale (RSE). Acceptance and commitment therapy measures package. 1965;61:52.

22. Çuhadaroğlu F. Adolesanlarda benlik saygısı. Uzmanlık Tezi. Ankara: Hacettepe Üniversitesi Tıp Fakültesi Psikiyatri Anabilim Dalı; 1986.

23. Hollingshead AB, Redlich FC. Social class and mental illness: Community study. 1958.

24. Andreasen N. Comprehensive assessment of symptoms and history (Çev.: Tiryaki A). 1987.

25. Rey JM, Bella-Awusah TT, Liu J. DÉPRESSION DE L'ENFANT ET DE L'ADOLESCENT. 2012.

26. Rapee R. Anxiety disorders in children and adolescents: nature, development, treatment and prevention. 2012.

27. Polanczyk G, De Lima MS, Horta BL, Biederman J, Rohde LA. The worldwide prevalence of ADHD: a systematic review and metaregression analysis. Am J Psychiatry. 2007;164(6):942-948.

28. Quy K, Stringaris A. Oppositional defiant disorder. IACAPAP etextbook of child and adolescent mental health Geneva: International Association for Child and Adolescent Psychiatry and Allied Professions. 2012:1-14.

29. von Gontard A. The impact of DSM-5 and guidelines for assessment and treatment of elimination disorders. Eur Child Adolesc Psychiatry. 2013;22(1):61-67.

30. Ercan ES, Polanczyk G, Akyol Ardıc U, et al. The prevalence of childhood psychopathology in Turkey: a cross-sectional multicenter nationwide study (EPICPAT-T). Nord J Psychiatry. 2019;73(2):132-140.

31. Surer Adanir A, Taskiran G, Kupesiz OA, Özatalay E. Psychopathology in pediatric bone marrow transplantation survivors and their mothers. Pediatr Int. 2017;59(9):979-985

32. Zanato S, Traverso A, Tremolada M, et al. Psychopathological aspects in childhood hematopoietic stem cell transplantation (HSCT): The perception of parents and adolescents. Front Psychol. 2017;8:272.

33. Nylander C, Fernell E, Tindberg Y. Chronic conditions and coexisting ADHD-a complicated combination in adolescents. Eur J Pediatr. 2015;174(9):1209-1215

34. Hutt D, Nehari M, Munitz-Shenkar D, Alkalay Y, Toren A, Bielorai B. Hematopoietic stem cell donation: psychological perspectives of pediatric sibling donors and their parents. Bone Marrow Transplant. 2015;50(10):1337-1342.

35. Phipps S, Brenner M, Heslop H, Krance R, Jayawardene D, Mulhern R. Psychological effects of bone marrow transplantation on children and adolescents: preliminary report of a longitudinal study. Bone Marrow Transplant. 1995;15(6):829-835

36. Packman W, Gong K, VanZutphen K, Shaffer T, Crittenden M. Psychosocial adjustment of adolescent siblings of hematopoietic stem cell transplant patients. J Pediatr Oncol Nurs. 2004;21(4):233-248.

\section{SUPPORTING INFORMATION}

Additional supporting information may be found online in the Supporting Information section at the end of the article.

How to cite this article: Erden S, Kuşkonmaz BB, Çetinkaya DU, Ünal F, Özsungur B. Pediatric bone marrow transplantation: Psychopathologic features in recipients along with siblings. Psycho-Oncology. 2019;28:1995-2001. https://doi.org/ 10.1002/pon.5179 